\title{
IMMUNITY LEVEL TO HEPATITIS B VIRUS IN VACCINATED MEDICAL STUDENTS
}

\author{
${ }^{1}$ Abdolreza Sotoodeh Jahromi, ${ }^{2}$ Alireza Makarem, \\ ${ }^{1}$ Karamatollah Rahmanian and ${ }^{3}$ Abdoulhossein Madani \\ ${ }^{1}$ Research Center for Social Determinants of Health, \\ ${ }^{2}$ Department of Immunology, Student Research Committee, Faculty of Medicine, \\ Jahrom University of Medical Sciences, Jahrom, Iran \\ ${ }^{3}$ Department of Public Health, Faculty of Hygiene, Hormozgan University of Medical Sciences, Bandarabbas, Iran
}

Received 2012-07-23, Revised 2012-10-29; Accepted 2013-07-19

\begin{abstract}
Hepatitis B is a wide world disease and more than $1 / 3$ of people in the world are HBs Ag positive. HBV causes chronic hepatitis, acute hepatitis, chronic cirrhosis and hepatocellular carcinoma in adults and children. This research was done for evaluation of immunogenicity of HBV vaccine with $\mathrm{HBs} A b$ measurement after vaccination. This descriptive cross-sectional study was done on 135 medical students of Jahrom University of medical science who had been vaccinated three times. The obtained serum was tested by Elisa method to determine for Anti-HBs antibodies. All collected data were entered in statistical software program SPSS (version 16) and were analyzed by descriptive statistics and chi-square and t-test. Out of 135 medical students, $102(75.6 \%)$ were women. In this study $13(9.6 \%)$ subjects had anti-HBs titer of 10$100\left(\mathrm{mIu} \mathrm{mL}^{-1}\right)$ and $122(90.4 \%)$ subjects had anti-HBs titer of $>100 \mathrm{mIu} \mathrm{mL} \mathrm{m}^{-1}$. There was no correlation between immunity level and age, sex, BMI, time after last vaccination and past record of needle stick at work place. Although immunity to hepatitis B was in protective level among all participants, assessment of immunity in healthcare workers after complete vaccination recommended.
\end{abstract}

Keywords: HBV, Immunity, Vaccination, Medical Students

\section{INTRODUCTION}

Hepatitis B infection play a significant role to disturbe public health (Zajac et al., 1986). Despite acute infection, severe morbidity and mortality from cirrhosis and hepatocellular carcinoma is more common in Chronic HBV infected people. Hepatitis $B$ is an significant, infectious, for healthcare workers and medical students unprotected to human blood (Gunson et al., 2003). The high prevalence of virus carriers in the supported population (Zaman, 2006) the high frequency of exposure to blood and other human fluids, needle stick and sharps injuries at work place and the highly contagious nature of Hepatitis B Virus (HBV) is the risk of infection. Universally, it is estimated that more than 2 billion persons have evidence of past HBV infection, more than 350 million are chronic carriers and each year one million deaths occur by HBV-related diseases (Zuckerman et al., 2007). Studies display that, the prevalence of HBs Ag with moderate endimicity in different part of Iran is 2-7\% (Hou et al., 2005). In a study among Indonesian health-care workers in 2005, sharp injuries led to an estimated 1445 infections with HBV (Agustian et al., 2009). Sobia et al. (2011) study HCWs showed $2.18 \%$ prevalence of positive HBV. In a study conducted in pakistan the main promotion factors for HBV was unscreened blood transfusion 56 (27.86\%) (Tassaduqe et al., 2004). Since 1982, considerable progress has been made to reducing the risk for HBV infection in adults and eliminating HBV transmission in children (Armstrong et al., 2001).

Although many progresses has been made in medical science but there is no effective treatment for Hepatitis B infection yet, so immunization, by means of recombinant

Corresponding Author: Alireza Makarem, Research Center for Social Determinants of Health,

Jahrom University of Medical Sciences, Jahrom, Iran 
vaccination, is necessary to prevent the clinical disease, the progress of carriers and the transmission of the HBV to high risk persons. Cause, medical and paramedical students are at risk of exposure to vaccine-preventable diseases the vaccination by Healthcare Workers (HCWs) is very necessary for hospitals (Stewart et al., 2002; Askarian and Malekmakan, 2006). Host factors that may affect the immune response include: increasing age, smoking cigarettes, obesity and having a medical disorder that compromises the immune system (Zajac et al., 1986). In a study in Lahore, Pakistan only $42.2 \%$ of medical student and $49.0 \%$ of healthcare workers were vaccinated (Nasir et al., 2000).

Although different studies show high rates of immunization after a three-dose vaccination program, more than $10 \%$ may have non protective antibody titers (Zajac et al., 1986).

As there was no study on the immunity level to hepatitis B virus in hbv vaccinated medical students in this area and also there is no information about HBV immunity status of these students.

So the present study was conducted to determine the serum HBs Ab levels and HBV immunity status in the medical students following vaccination. This is the frist study about determination immunity level to HBV in vaccinated medical students in south of Iran.

\section{MATERIALS AND METHODS}

This descriptive and cross-sectional study was carried out during January-February 2010 at Motahari and Peymaineh Hospitals. One hundred-thirty and five medical students of Jahrom University of medical science who had been vaccinated three times were enroled in this study. All participants provided informed consent, allowing access to their hepatitis B antibody titer results. The study was approved by the appropriate ethics committees. All students present were asked to complete a self-administered, anonymous questionnaire containing: Age, sex, BMI and duration from last vaccination. Heights and weights were measured to the nearest $0.1 \mathrm{~cm}$ and $0.1 \mathrm{~kg}$, respectively, by the research team, using a SECA-marked stadiometer.

Body Mass Index (BMI), calculated as weight in kilograms divided by squared height in meters system $\left(\mathrm{kg} \mathrm{m} \mathrm{m}^{-2}\right.$ ), was determined for each subject (Garrow, 1983). According to their BMI, subjects were divided to:

Underweight (18.49 $\geq \mathrm{BMI}), \quad$ normal $(18.5 \leq \mathrm{BMI} \leq 24.9)$, Overweight $(25 \leq \mathrm{BMI} \leq 29.9)$ and obese $(30 \leq \mathrm{BMI})(15)$. HBs-Ab titers were determined by enzyme linked immunosorbent assay (ELISA) method by use of Diapro kit (CE-0318, Italy). According to the serum HBs-Ab levels, the subjects population was classified as non-immune (less than $10 \mathrm{mIU} \mathrm{mL}^{-1}$ ); moderately immune (between 10 and $100 \mathrm{mIU} \mathrm{mL}^{-1}$ ) and fully immune (more than $100 \mathrm{mIU} \mathrm{mL}^{-1}$ ).

Participants who were $\mathrm{HBs} \mathrm{Ag}$ positive as well as subjects which did not receive vaccination or those who had incomplete vaccination against the HBV and subjects who had no tendency to enter this study were excluded. All collected data were entered in statistical software program SPSS (version 16) and were analyzed by descriptive statistics, chi-square and t-test.

\section{RESULTS}

Among 135 medical students, 33 (24.4\%) were male and $102(75.6 \%)$ were female. The mean age $( \pm$ SD) was $23.6 \pm 1.5$ years. According to the results of serologic tests, all of participants showed seropositivity for HBV infection. Thirteen subjects $(9.6 \%)$ were moderately immune and 122 subjects $(90.4 \%)$ were fully immune. So, the majority of our study students fell outside the fully immune group.

Mean age of the subjects in moderately immune group was $24.10 \pm 2$ years and in the fully immune group was $23.50 \pm 1.4$ years $(\mathrm{p}>0.05)$.

In our study there was a higher percentage of males in the fully immune category $(93.9 \%)$, but there was no significant association between sex and HBsAb Level ( $p>0.05)$.

One hundred and twenty six students had normal weight $(18.5 \leq \mathrm{BMI} \leq 24.9)$ in which $115(91.3 \%)$ of them were fully immune. There was no significant association between BMI and HBs-Ab level ( $p>0.05)$ (Table 1).

Table 1. Frequency of immunity against hepatitis B in medical

\begin{tabular}{|c|c|c|c|c|}
\hline & & $\begin{array}{l}\text { Moderately } \\
\text { immune no (\%) }\end{array}$ & $\begin{array}{l}\text { Fully immune } \\
\text { no }(\%)\end{array}$ & $\begin{array}{l}\text { Total } \\
\text { no }(\%)\end{array}$ \\
\hline \multirow[t]{3}{*}{ Sex } & Male & $2(6.1 \%)$ & $31(93.9 \%)$ & $33(100 \%)$ \\
\hline & Female & $11(10.8 \%)$ & $91(89.2 \%)$ & $102(100 \%)$ \\
\hline & Total & $13(9.6 \%)$ & $122(90.4 \%)$ & $135(100 \%)$ \\
\hline \multirow[t]{5}{*}{ BMI } & $\begin{array}{l}\text { Underweight } \\
(18.49) \leq \mathrm{BMI}\end{array}$ & $0(0 \%)$ & $3(2.5 \%)$ & $3(2.5 \%)$ \\
\hline & $\begin{array}{l}\text { Normal } \\
(18.5 \leq \mathrm{BMI} \leq 24.9)\end{array}$ & $11(8.7 \%)$ & $115(91.3 \%)$ & $126(93.3 \%)$ \\
\hline & $\begin{array}{l}\text { Overweight } \\
(25 \leq \mathrm{BMI} \leq 29.9)\end{array}$ & $2(40 \%)$ & $3(60 \%)$ & $5(3.7 \%)$ \\
\hline & Obese $(30 \leq \mathrm{BMI})$ & $0(0 \%)$ & $1(100 \%)$ & $1(0.7 \%)$ \\
\hline & Total & $13(9.6 \%)$ & $122(90.4 \%)$ & $135(100 \%)$ \\
\hline
\end{tabular}

All $\mathrm{P}$ values were not significant $(>0.05)$ 
Mean time after last vaccination in moderately immune subjects was $51.9 \pm 13.3$ month and in fully immune subjects was $48 \pm 15.1$ month ( $\mathrm{p}>0.05)$.

\section{DISCUSSION}

The results of this study were were agree to the results of other researches were done in other cities of Iran. The immunity status of HBV vaccine among three time vaccinated medical students in different cities of Iran are: Mazandaran (98.4\%), Borojerd (90\%), Rasht (95.1\%), Hamadan (94\%) (Ghavamian and Khaki, 2005; Ghanaei et al., 2006; Ranjbar et al., 2002).

In different countries worldwide immunization of $\mathrm{HBV}$ vaccine on HCWs is acceptable: Michigan of America (85.8\%), Italy (81.6\%) and Brazil (93.3\%) (Havlichek et al., 1997; Floreani et al., 2004; Tele et al., 2007).

Ghorbani et al. (2008) study found that two doses of HBV vaccine can produce immunity for five years compare to one dose of vaccine.

Louther et al. (1998) study in New York City hospital increasing age was the only risk factor for lesser response to HBV Vaccine.

Results of two studies on health care workers and one study on medical students about immunization of HBV Vaccine in Yasuj, Shahrekord and Rasht cities of Iran respectively, showed that females had higher titer than male (Sarkari et al., 2007; Parmar et al., 2011; Ghanaei et al., 2006).

Martinez et al. (1998) study showed that increasing $\mathrm{BMI}$ is a risk factor for lesser response to HBV Vaccine.

In our study there was no significant association between immunity level and age, sex, BMI and time after last vaccination in this study122 subjects had antiHBs titer> $100 \mathrm{IU} \mathrm{L}^{-1}$.

Although Results of our study and other studies in Iran and other countries mentioned above shows a good response to $\mathrm{HBV}$ vaccine in $\mathrm{HCWs}$; but as a high risk group evaluation of HBs-Ab should be considered after vaccinations in these subjects and also continuation of anti-HBV vaccination in spread program of immunization in Iran is recommended.

\section{CONCLUSION}

According to our results (more than $90 \%$ full immunity) hepatitis B vaccines have a good highly immunogenicity and its immunogenicity has not any difference in male and female genders. The main mission of this study is concluded as.
As medical students are a high-risk group to be contaminated by $\mathrm{HBV}$, it is preferable to be evaluated for anti-HBs titer 1-3 months after full three- dose $(0,1$ and $6)$ vaccination especially when these factors are present.

\section{ACKNOWLEDGMENT}

We would like to thank all students who accepted to enter in this study and we thank Student Research Committee of Jahrom University of Medical Sciences for financing of this research.

There is no conflict for this study.

\section{REFERENCES}

Agustian, D., S. Yusnita, H. Susanto, H. Sukandar and A. De Schryver et al., 2009. An estimation of the occupational risk of $\mathrm{HBV}, \mathrm{HCV}$ and $\mathrm{HIV}$ infection among Indonesian health-care workers. Acta Med. Indones, 41: 33-37. PMID: 19920296

Armstrong, G.L. E.E. Mast, M. Wojczynski and H.S. Margolis, 2001. Childhood hepatitis B virus infections in the United States before hepatitis B immunization. Pediatrics, 108: 1123-1128. DOI: 10.1542/peds.108.5.1123

Askarian, M. and L. Malekmakan, 2006. The prevalence of needle stick injuries in medical, dental, nursing and midwifery students at the university teaching hospitals of Shiraz, Iran. Indian J. Med. Sci., 60: 227-232. DOI: 10.4103/0019-5359.25904

Floreani, A., V. Baldo, M. Cristofoleeti, G. Renzulli and A. Valeri et al., 2004. Long-term persistence of anti-HBS after Vaccination against HBV: An 18 year experience in health care workers. Vaccine, 22: 608-611. DOI: 10.1016/j.vaccine.2003.09.001

Garrow, J.S., 1983. Indices of adiposity. Nutr. Abstr. Rev. Ser. A., 53: 697-708.

Ghanaei, F., M. Falah, F. Jokar, R. Jafarshad and M. Arami et al., 2006. The immunologic response to Anti-Hepatitis B vaccination among medical students of Guilan University of Medical Sciences, Guilan, Iran. Hepat. Monthly, 6: 63-66.

Ghavamian, M. and M. Khaki, 2005. Evaluation of recombinant HBS Ag vaccine immunity in students of Medicine and the staffs, vaccinated in Borujerd Hospital. Med. Sci. Islamic Azad Univ. Mashhad, 3: 69-74. 
Ghorbani, G.A., S.M. Alavian and H.R. Ghadimi, 2008. Long term effects of one or two doses of hepatitis B Vaccine in adults after five years. Pak. J. Biol. Sci., 11: 660-663. DOI: 10.3923/pjbs.2008.660.663

Gunson, R.N., D. Shouval, M. Roggendorf and H. Zaaijer et al., 2003. Hepatitis B Virus (HBV) and Hepatitis C Virus (HCV) infections in Health Care Workers (HCWs): Guidelines for prevention of transmission of $\mathrm{HBV}$ and $\mathrm{HCV}$ from $\mathrm{HCW}$ to patients. J. Clin. Virol., 27: 213-230. DOI: 10.1016/S1386-6532(03)00087-8

Havlichek, Jr. D., K. Rosenman, M. Simms and P. Guss, 1997. Age-related hepatitis B seroconversion rates in health care workers. Am. J. Infect. Control., 25: 418-420. DOI: 10.1016/S0196-6553(97)90090-0

Hou, J., Z. Liu and F. Gu, 2005. Epidemiology and prevention of hepatitis B virus Infection. Int. J. Med. Sci., 2: 50-57. PMCID: 1142225

Louther, J., J. Feldman, P. Rivera, N. Villa and J. DeHovitz et al., 1998. Hepatitis B vaccination program at a New York City hospital: Seroprevalence, seroconversion and declination. Am. J. Infect. Control, 26: 423-427. DOI: 10.1016/S0196-6553(98)70039-2,

Martinez, N.T., G.M.T. Burillo, B.P. Bermudez and J.B.S. Alvarez, 1998. Factors associated with inadequate response to hepatitis $\mathrm{B}$ vaccination in health care personnel. Rev. Esp. Salud. Publica., 72: 509-515. PMID: 10050601

Nasir, K., K.A. Khan, W.M. Kadri, S. Salim and K. Tufail et al., 2000. Hepatitis B vaccination among health care workers and students of a medical college. J. Pak. Med. Assoc., 50: 239-243. PMID: 10992702

Parmar Z., R. Khadivi, B. Sadeghi and M. Rahimi Madiseh, 2011. Immunization following hepatitis $b$ mass vaccination in the 18 years old students in chaharmahal va bakhtyari province in Iran. J. Shahrekord Univ. Med. Sci., 13: 35-41.

Ranjbar, M., F. Keramat and F. Keshavarz, 2002. The immunogenic of Hepatits B vaccine in personnel of Sina Hospital of Hamedan. Iranian J. Infect. Dis. Tropical Med., 7: 55-58.
Sarkari, B., M.A. Zargar, R. Mohammadi and S.H. Asgarian, 2007. Prevalence of Hepatitis B antibodies in health-care workers in Yasuj hospitals. armaghane-danesh J. Yasuj Univ. Med. Sci., 11: $97-$ 106.

Sobia, A., S. Khan, Naseemullah, A. Sultan and K. Shahid et al., 2011. Prevalence of HBV and HBV vaccination coverage in health care workers of tertiary hospitals of Peshawar, Pakistan. Virol. J., 8: 275-275.

Stewart, S., S.B. Murray and S.A. Skull, 2002. Evaluation of healthcare worker vaccination in a tertiary Australian hospital. Int. Med. J., 32: 585592. DOI: 10.1046/j.1445-5994.2002.00288.X

Tassaduqe, K., M. Ali, A. Salam, H. Kalsoom and A. Salam et al., 2004. Studies on the prevalence of hepatitis B virus in relation to sex, age, Promotive factors, associated symptoms and season among human urban. J. Med. Sci., 4: 183-187. DOI: 10.3923/jms.2004.183.187

Tele, S.A., R.M. Martins, C.L. Lopes, M.A.D.S. Carneiro and K.P. Souza et al., 2007. Immunogenicity of a recombinant hepatitis B vaccine (Eu vax-B) in haemodialysis patients and staff. Eur. J. Epidemiol., 17: 145-149.

Zajac, B.A., D.J. West, W.J. McAleer and E.M. Scolnick, 1986. Overview of clinical studies with hepatitis B vaccine made by recombinant DNA. J. Infect., 13: 39-45. DOI: 10.1016/S01634453(86)92668-X

Zaman, R.U., 2006. Prevalence of hepatitis B and hepatitis $\mathrm{C}$ viruses in human urban population of Bahawalpur district, Pakistan. J. Med. Sci., 6: 367-373.

Zuckerman, J., J. Van Hattum, M. Cafferkey, I. Gjorup and T. Hoel et al., 2007. Should hepatitis B vaccination be introduced into childhood immunisation programmes in northern Europe? Lancet Infect. Dis., 7: 410-419. DOI: 10.1016/S1473-3099(07)70136-6 